\title{
IOWA: Intuitive-Use Oriented Webtool for the Creation of Adapted Contents (in an E-learning Environment)
}

\author{
Sergio Ocio Barriales, $M^{\mathrm{a}}$ del Puerto Paule Ruiz, Martín González Rodríguez, \\ Juan Ramón Pérez Pérez, and David Tuñón Fernández \\ HCI Group- Labtoo- Dpto. Computer Science \\ C/Calvo Sotelo S/N Facultad de Ciencias. 33007 Oviedo. Spain \\ djrekcv@terra.es, \{paule, martin, jrpp\}@pinon.ccu.uniovi.es, \\ davidtfatelecable.es
}

\begin{abstract}
In this paper, we propose to include adaptation, in particular to the laearning styles, to traditional e-learning systems in order to get a new application which adapts its contents to the user instead of being the user who adapts his habits to what the system requires. We also present the Intuitive-use Oriented Webtool for the creation of Adapted contents (in an e-learning environment), a.k.a. IOWA, an application which allows teachers to create adapted contents which will be showed later to students depending on the style they belong to.
\end{abstract}

\section{Introduction}

Nowadays, there are many applications which allow to offer distance learning (elearning) as another system which can be used by the teaching community to accomplish their task. However, these systems are not fully perfected, because they force both students and teachers to change their normal behavior to work as the system requires. Due to these limitations, actual e-learning does not reach the level effectiveness got by traditional teaching, in which there are a wider freedom to work as each wants to.

Feijoo.net has being developed to cover these deficiencies, offering in a single system all that was offered by traditional distance learning systems and a model of adaptation to the learning styles. This makes the system to adapt to its users' neccesities rather than the inverse way. IOWA is the component of Feijoo.net which task is the creation of contents, so it will be mainly used by teachers. 


\section{A Model of Adaptation: CHAEA's Test}

Each person has his own way to learn new concepts, which makes the learning be successful in less time or easier. This 'tricks' are called learning styles [1]. Basing on this concept, we need a classification which allows us to group people depending on their learning style.

CHAEA's test [2] offers a classification that divides all the possible ways to learn in four groups: theoretician, active, reflexive and pragmatic. CHAEA's test in focused in how teachers would work with students in a class.

In addition, this test is leaned to university students and has been proved in Spanish Universities, so we have decided to use this classification instead of others like VARK [3].

\section{System's Architecture}

Our system's architecture is made following the pattern model-view-controller. The core of IOWA is composed by four subsystems:

\subsection{Creation of Contents Subsystem}

As in all e-learning systems, contents are a key part of Feijoo.net. IOWA provides editors to create both text contents and to purpose exercises to strengthen student's knowledge. The biggest difference is that, while other system's contents are common for all their users, in Feijoo.net there can be a common part and a specific part. When a student requested these contents, the system will show automatically the common part and the specific for that kind of user (depending on the learning style), creating this way different contents for each style without bothering teachers as they do not need to worry about how adaptation is actually done.

Our studies have demonstrated that presenting information that is adapted to the learning style of the user improves learning. However, with exercises this is not this way, because any student can do any exercise even if that exercises was not planned for that kind of user; when a concept is assimilated, it does not matter how a student is asked about it, because he/she should know the answer. So, exercises will be common to all users in Feijoo.net.

\subsection{Organization of Contents Subsystem}

Once all contents have been created, the teacher can create a new planning for the didactic unit he is working with. This way, he/she can control in which order the contents may be shown to his/her students, how can a student go through those contents and even decide if certain contents are interesting or not to a specific learning style. Using an acyclic graph, which can be easily created through an editor, provided by IOWA, this planning, is described. There must be a planning for each learning style. This gives the teacher another tool to create contents that are even more adequate to 
his/her students. This planning concept fits with context concept from OOHDM [4]. In Feijoo.net, each learning style has its own context for each didactic unit, as for each style it will be specified what contents will be shown and in which order.

\subsection{Templates of Visualization Subsystem}

All Feijoo.net data is saved as XML. This is very beneficial, because data can be process in a very easy way.

This subsystem takes advantage of this property, providing a simple wizard-like interface to create a XSLT template that, applied to the XML obtained from our database produces that contents can be shown as the teacher wants.

Although a default template is provided to teachers, they can create all the ones they want. Then, they can select one of these templates to be used with a course. Teachers have the option to preview what format any existing template applies.

\subsection{Preview Subsystem}

This subsystem will allow the teacher to "visit" the didactic unit's contents as if he/she was a student. After selecting a learning style to preview, IOWA will generate the final results after linking contents, planning and template, offering the possibility of checking if everything is as the teacher wanted.

Providing this subsystem completes the tool and makes the teacher to feel more comfortable with IOWA, as she/he can see what the result of his/her work is.

\subsection{Other Components}

IOWA has other secondary components to offer a full editing system:

- System's help: IOWA has a context-sensitive help system in which teachers can learn to do any action offered in the application, though all the system has been developed having its users in mind; usability is one of its improved features.

- Error manager: it provides explanation for each error that can be present in the system and avoids the system to crash.

- Teacher-guide system: as its name points, this system guides the teacher through each step at the time of offering new contents to students. It remembers where a teacher has left his/her work last time when he/she reenters the system and advises him/her about what is the best path to follow to accomplish his/her task.

- Database-access web service: in order to centralize all the access to Feijoo.net database, we have created a Web Service built on .NET framework. It accepts a SQL sentence as input and outputs the query's results as XML. Teachers will not know how the system works internally, but this system is one of the most important components of all Feijoo.net. 


\section{Conclusions and New Features}

Adding some kind of adaptation to distance learning systems can improve a lot the quality of this kind of teaching, as Feijoo.net tries to demonstrate.

IOWA gets that the task of creating new on-line contents could be much more powerful, because the behavior of the system when it is being used by some kind of student can be determined and, despite this, the task does not get more work to be done, because a great part of this adaptation is made automatically by the system.

We think that adaptation is the next way to follow in e-learning systems if they want to offer teaching with the same quality it would have if it was given in a traditional way.

\section{References}

1. Learning Styles. http://galeon.hispavista.com/pcazau/guia_esti01.htm.

2. CHAEA's test. Deusto University. http://www.ice.deusto.es/guia/test0.htm.

3. VARK. http://www.vark-learn.com.

4. The Object-Oriented Hypermedia Design Model (OOHDM). Rossi, G.; Schwabe, D.. http://www.telemidia.puc-rio.br/oohdm/oohdm.html

\section{Other References}

5. Paul De Bra and Licia Calvi. "Towards a Generic Adaptive Hypermedia System" in Proceedings of the Second Workshop on Adaptive Hypertext and Hypermedia, Pittsburgh, PA, 5-11, 1998.

6. Del Moral Pérez and et.all (2002):"Rur@lnet: Un espacio para la teleformación y el trabajo colaborativo". En 2nd European Congress on Information Technologies in Education and Citizenship: a critical insight.

7. Del Moral Pérez, M. Esther; Álvarez Fernández, Susana (2002): "Generación de entornos de teleformación y atención a la diversidad cognitiva de los usuarios". En Comunicación y Pedagogía . 